\title{
rommhalina
}

(8)

\section{Marca-lugar Muhipiti}

Autor(es): $\quad$ Rebelo, Helena Soares; Gonçalves, Nuno Simão

Publicado por: Imprensa da Universidade de Coimbra

URL

persistente:

URI:http://hdl.handle.net/10316.2/44320

DOI:

DOI:https://doi.org/10.14195/978-989-26-1556-1_15

Accessed : $\quad$ 26-Apr-2023 10:53:23

A navegação consulta e descarregamento dos títulos inseridos nas Bibliotecas Digitais UC Digitalis, UC Pombalina e UC Impactum, pressupõem a aceitação plena e sem reservas dos Termos e Condições de Uso destas Bibliotecas Digitais, disponíveis em https://digitalis.uc.pt/pt-pt/termos.

Conforme exposto nos referidos Termos e Condições de Uso, o descarregamento de títulos de acesso restrito requer uma licença válida de autorização devendo o utilizador aceder ao(s) documento(s) a partir de um endereço de IP da instituição detentora da supramencionada licença.

Ao utilizador é apenas permitido o descarregamento para uso pessoal, pelo que o emprego do(s) título(s) descarregado(s) para outro fim, designadamente comercial, carece de autorização do respetivo autor ou editor da obra.

Na medida em que todas as obras da UC Digitalis se encontram protegidas pelo Código do Direito de Autor e Direitos Conexos e demais legislação aplicável, toda a cópia, parcial ou total, deste documento, nos casos em que é legalmente admitida, deverá conter ou fazer-se acompanhar por este aviso. 


\section{OFICINAS DE \\ MUHIPITI \\ planeamento estratégico \\ património \\ desenvolvimento}

organização:

Walter Rossa

Nuno Lopes

Nuno Simão Gonçalves

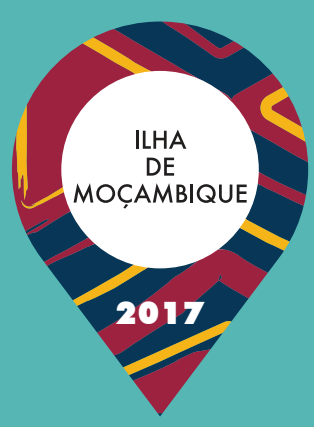




\title{
MARCA-LUGAR MUHIPITI
}

\author{
Helena Soares Rebelo \\ Nuno Simão Gonçalves
}

Oficina pós-evento

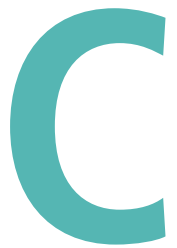

omo ficou dito na Introdução, a elaboração e publicação deste texto corresponde a uma decisão da coordenação do evento e dos organizadores do livro posterior àquele, e resulta da constatação da existência de um trabalho continuado, desde o início do projeto, de construção de uma imagem para o Oficinas, mas também para a llha. Importa esclarecer, desde logo, que a adoção da expressão Muhipiti, usada na língua local para designar a Ilha, resultou essencialmente de três fatores: a sua maior comunicabilidade expressiva, ou seja, a facilidade de uso e de memorização exclusiva (por oposição a Ilha de Moçambique); o estabelecimento de uma diferenciação clara entre uma ação não oficial (como é a nossa e que, pelo menos por enquanto, não é mais do que um exercício), e o que as entidades competentes possam estar a fazer no mesmo sentido; o reconhecimento implícito de expressões locais sob as oficiais, estabelecidas ao longo de um processo histórico que, se contêm a marca do colonialismo, também construíram a identidade e a própria designação do país. Isso não invalida que o caminho aqui proposto não possa ser trilhado com o recurso a outra designação, incluindo a mais comum e, apesar de tudo, equívoca (Ilha) ou a oficial (Ilha de Moçambique). 


\section{CONCEITO DE MARCA-LUGAR}

A ação continuada e consequente de planeamento estratégico necessária ao desenvolvimento sustentável da llha de Moçambique passa, entre muitas outras coisas como as já versadas neste livro, pela criação e promoção de uma marca-lugar (place branding) forte, que concorra para a dinamização e consolidação de uma imagem ambiental, social, económica e cultural positiva a nível global.

Numa definição/tradução de place branding, ainda pouco consolidada em língua portuguesa, o conceito de marca-lugar, como a própria designação indica, consiste num processo de construção de uma marca (branding) aplicada a um lugar (place), seja uma nação, uma cidade ou mesmo uma área urbana. O procedimento inclui o design (identidade visual, logótipo, slogan), o planeamento e a comunicação (marketing) de uma identidade local (Kavaratzis, 2009: 27) — neste caso fomos usando e testando Muhipiti - de forma a construir ou promover uma boa reputação do mesmo, não só para atrair investimento, como também para fortalecer a economia, a cultura e a autoestima das comunidades locais (Kavaratzis, 2004: 58; Anholt, 2006: 5).

Anholt (2006: 25-26) defende que uma identidade competitiva assenta em seis vértices de um hexágono que interagem entre si:

- Turismo: a forma como é promovido e qual a primeira impressão que os turistas formam do lugar;

- Políticas que apoiam e sustentam o investimento local;

- Marca: potencialidades ou vocações que distinguem e caracterizam o local;

- Investimento nacional e internacional no local;

- Trocas e atividades culturais que promovam e dinamizam a cultura endógena, não só in-loco, como aos níveis regional, nacional ou global;

- Habitantes e o seu engajamento no processo de promoção do lugar, na forma como recebem os visitantes e como incorporam a sua marca.

Este esquema hexagonal pode ser adaptado conforme as especificidades locais. No caso das cidades, as variantes dos vértices devem ajustar-se aos fatores que se pretende avaliar, realçar ou comparar. 


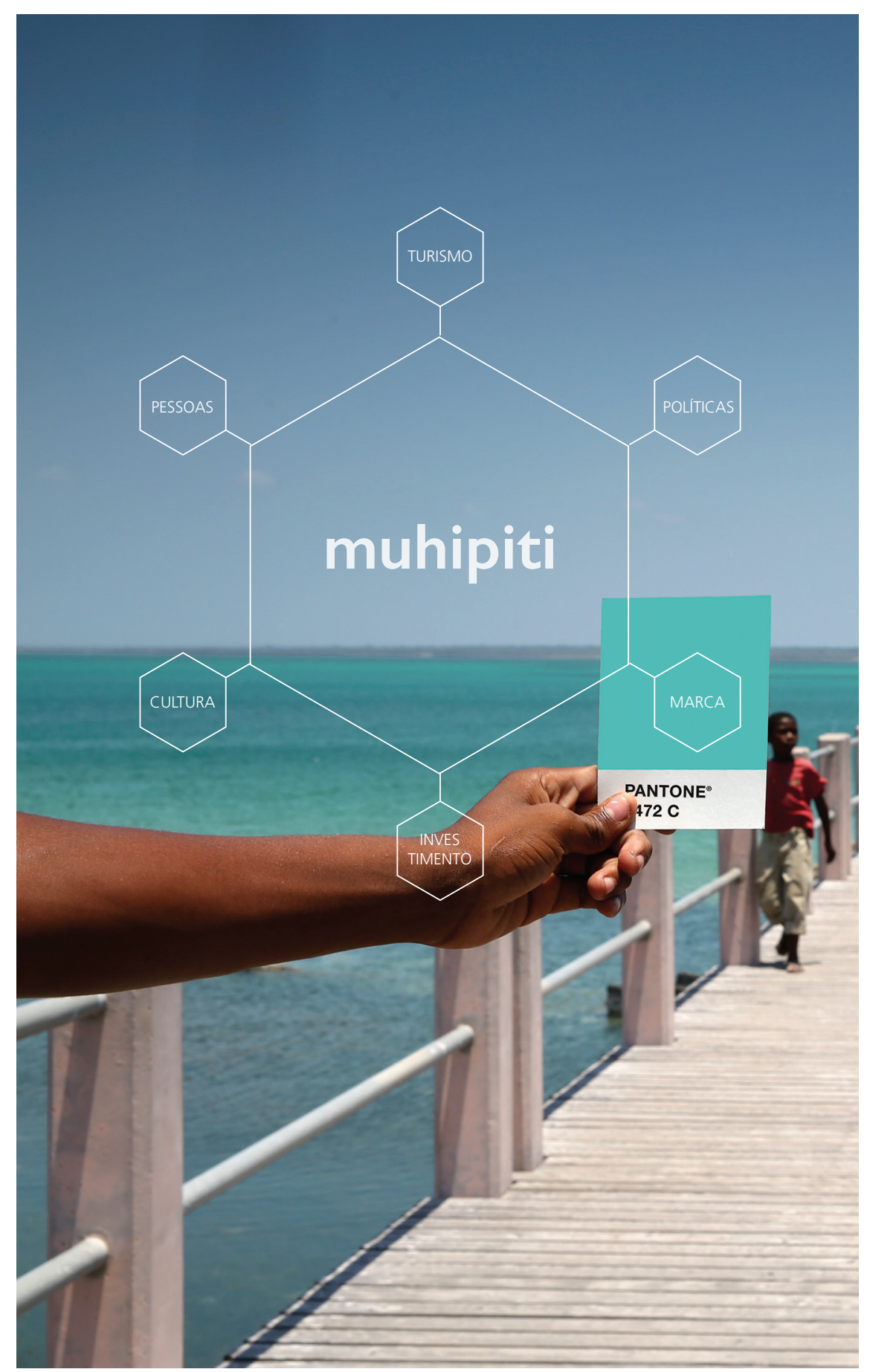




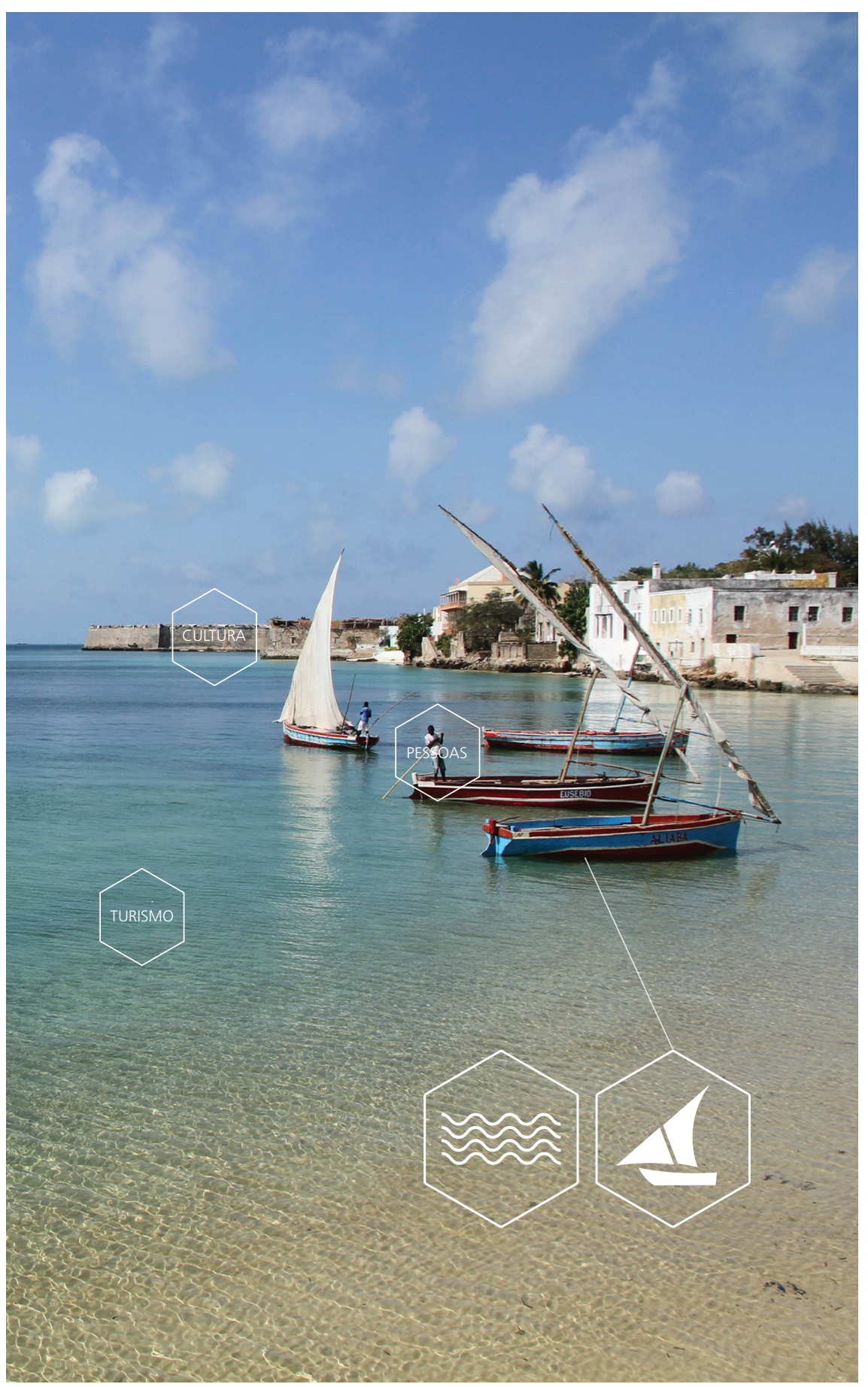




\section{BRANDING EM ÁFRICA}

No continente africano, os desafios para promoção e valorização dos lugares são prementes. A maioria dos países enfrenta problemas socioeconómicos e urbanos profundos que mobilizam e priorizam as políticas governamentais e dos financiadores externos. Muitos ainda se debatem com guerra, altos níveis de pobreza, iliteracia, corrupção, criminalidade, instabilidade económica e social, problemas que têm sido difundidos, enfatizados e gravados na opinião pública internacional desde meados do século passado (Youde, 2009: 127). Para inverter estes cenários é necessário que os países invistam na (re) construção de imagens otimistas dos seus territórios, conquistando a confiança dos investidores e visitantes internacionais e renovando a autoconfiança dos seus cidadãos (Wanjiru, 2006: 86-87).

A proximidade geográfica e cultural com a llha de Moçambique possibilita usar Zanzibar como exemplo comparativo para este estudo. Desde 2010 que a Comissão de Turismo de Zanzibar, em conjunto com os principais atores locais (designadamente agentes turísticos, tem vindo a criar uma marca única para a ilha ancorada em dois segmentos turísticos: cultura e história; sol e praia. O primeiro enfatiza não só a cidade de pedra (arquitetura e espaço urbano), inscrita desde 2000 na Lista do Património Mundial da UNESCO segundo os critérios ii, iii e vi (UNESCO, 2000), como também a rota das especiarias, a gastronomia, os festivais, as ruínas fora da cidade, as aldeias e mercados, o artesanato, a música, a população e a cultura swahili. Já a vertente sol e praia destaca as praias de areia branca, as águas transparentes e mornas de cor azul turquesa, o clima tropical, os bancos de coral ou de areia, as ilhas desertas e os barcos tradicionais, os dhows (Serengeti Advisers and Acorn Tourism Consulting, 2010: 29-32). É importante salientar que, apesar de Zanzibar ter duas universidades (uma privada e uma pública), que datam do final do século passado, não estão integradas nessa estratégia de promoção da cidade. 


\section{MARCA-LUGAR MUHIPITI PARA A ILHA DE MOÇAMBIQUE}

Para materializar uma marca-lugar para a Ilha de Moçambique é importante ter em conta os princípios defendidos por Anholt (2006: 25-26), dos quais aqui se destacam a necessidade de enaltecer as potencialidades e vocações que a distinguem e caracterizam, direcionando e/ou captando as políticas e os financiamentos para apoiar e sustentar o investimento local, nacional e internacional. É necessário fomentar atividades culturais (festivais, workshops, participação em redes) que promovam e dinamizem a marca, dando a conhecer características intangíveis que permanecem por explorar como, por exemplo, a dança de Tufo e a gastronomia da Ilha de Moçambique. Conforme já referido, será imprescindível o engajamento dos ilhéus de Moçambique, em particular representantes comunitários, comerciantes e agentes turísticos em todo o processo de promoção do seu território, de forma a, numa abordagem bottom-up, não só melhorarem a sua recetibilidade aos visitantes ou novos habitantes (Ministério da Cultura e Turismo, 2017: 54), como também assumirem o compromisso de incorporar e promover a marca-lugar. Além disto, este contributo comunitário poderá reforçar o seu sentimento de pertença e autoestima fortalecendo o caráter desta marca-lugar.

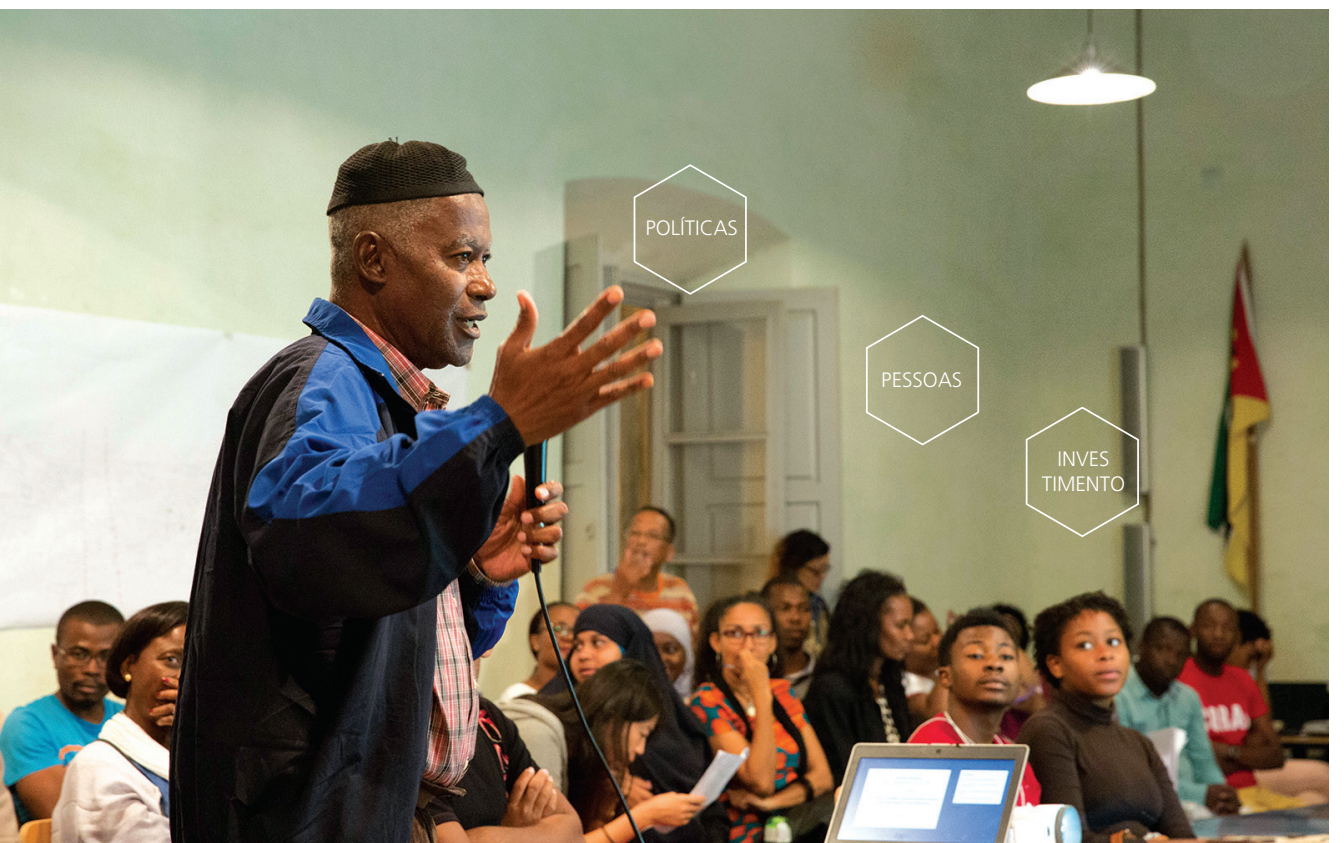




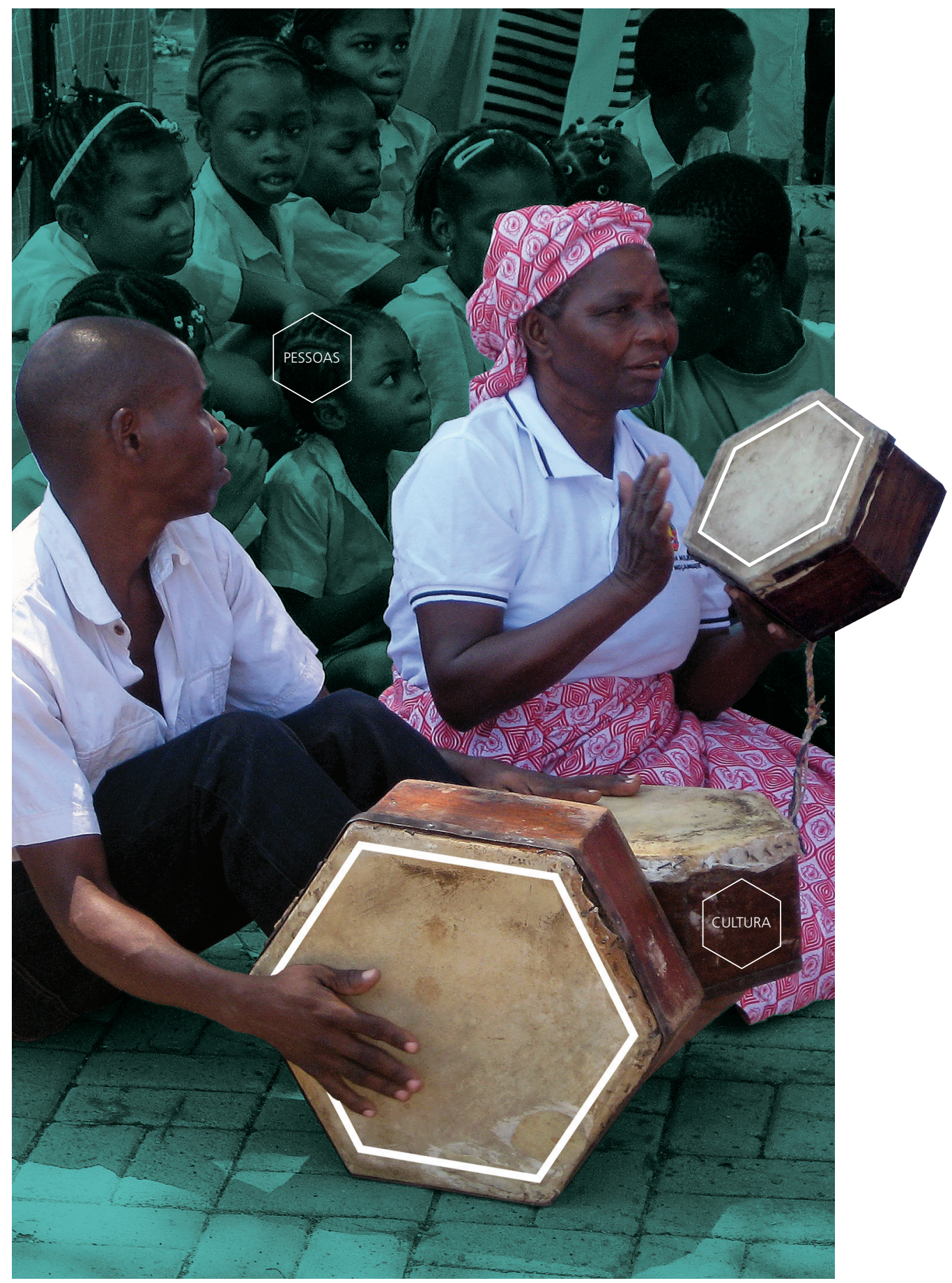




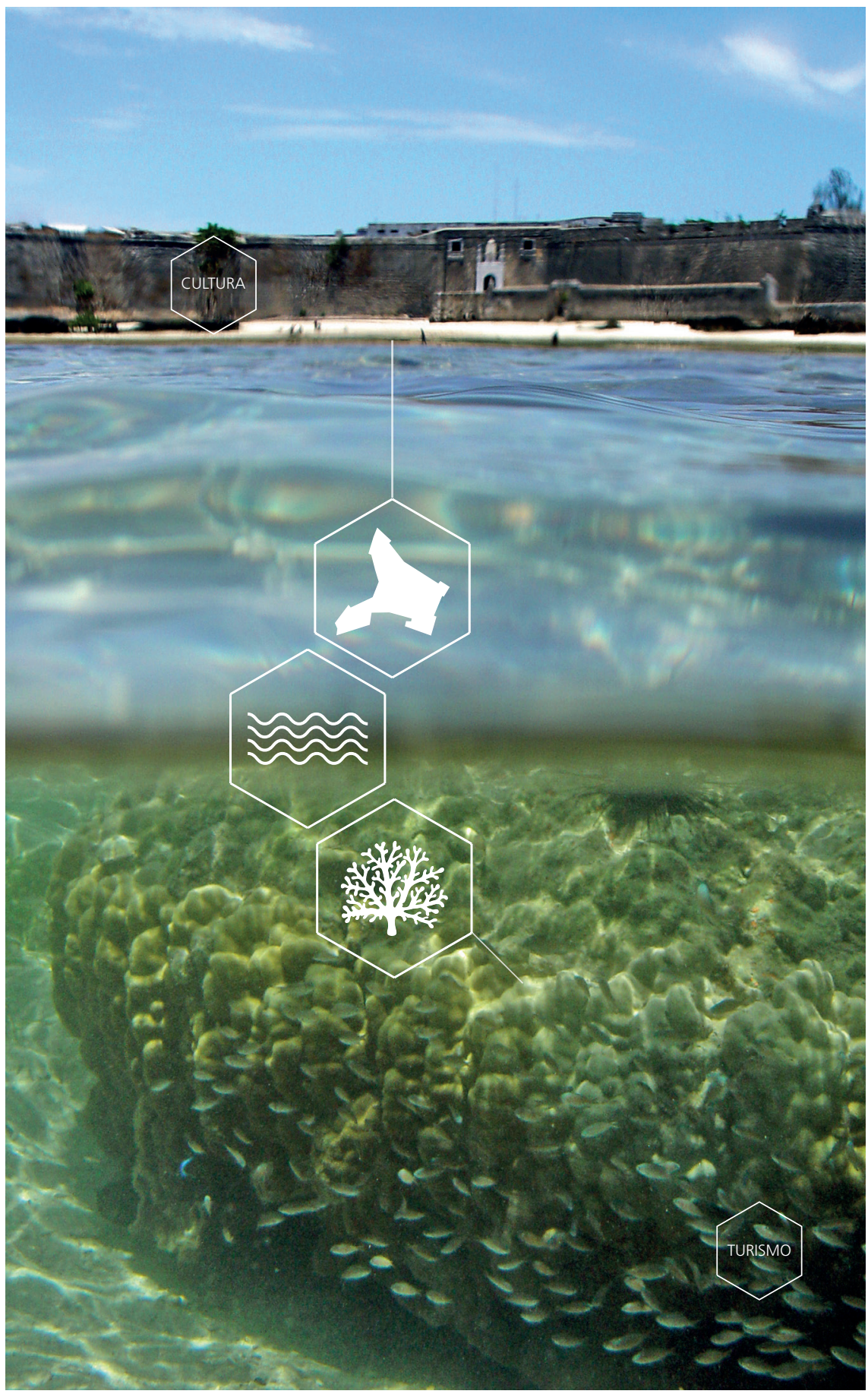




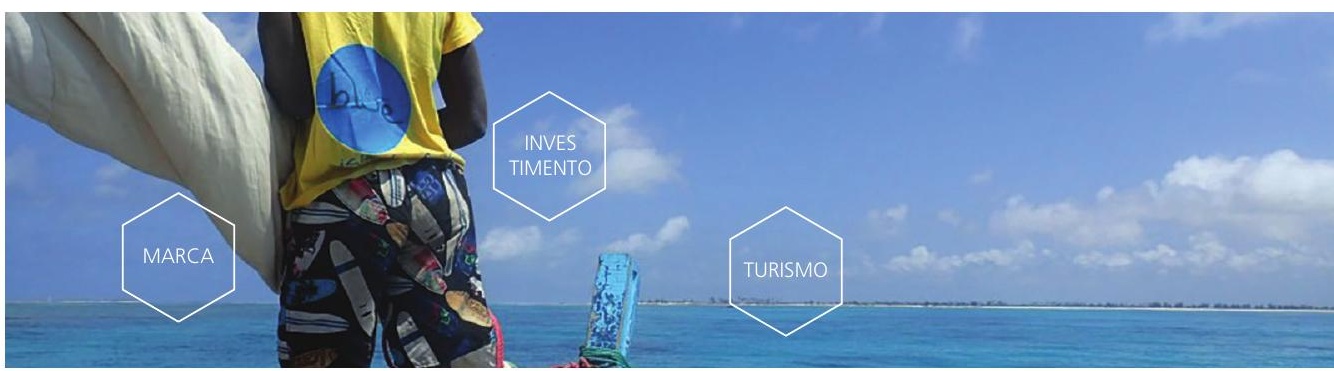

\section{POTENCIALIDADES E VOCAÇÕES DE MUHIPITI}

As potencialidades das zonas insular e continental abrangidas pela jurisdição da llha de Moçambique são várias e, conforme referido, deverão ser elencadas com a contribuição dos stakeholders, incorporando as suas sugestões e algumas ideias já em prática. Existem bons exemplos de trabalho de promoção turística já desenvolvidos, como a llha Blue, Genito Magic Tour (Genito Molava), Gito (António Giquira), entre outros.
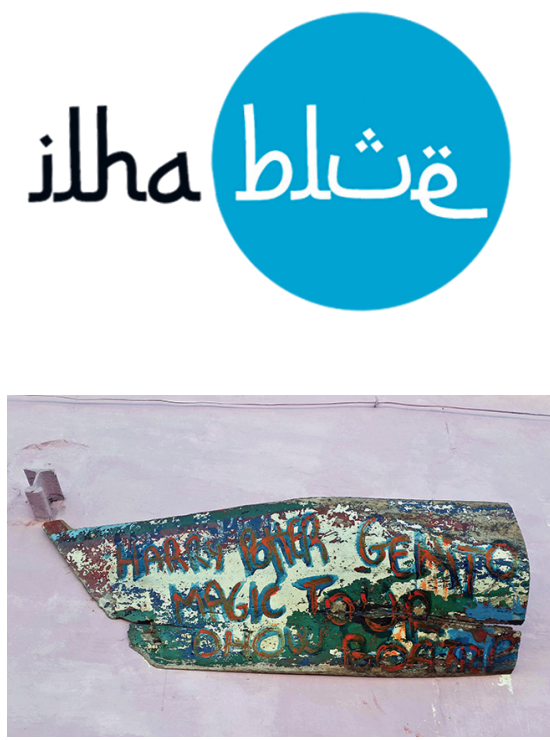

Nessa linha, dividimos algumas das potencialidades/vocações em três eixos, sabendo que num trabalho mais exaustivo outros deverão surgir:

- Eixo 1: formação avançada;

- Eixo 2: turismo e suas ramificações;

- Eixo 3: principais atividades económicas de captura e transformação de produtos endógenos (como a pesca, o sal, ou a castanha de caju).

A intenção é que estes eixos não se desenvolvam paralelamente, mas partilhem pontos sinergéticos, ajudando a atribuir consistência e coerência à marca. 


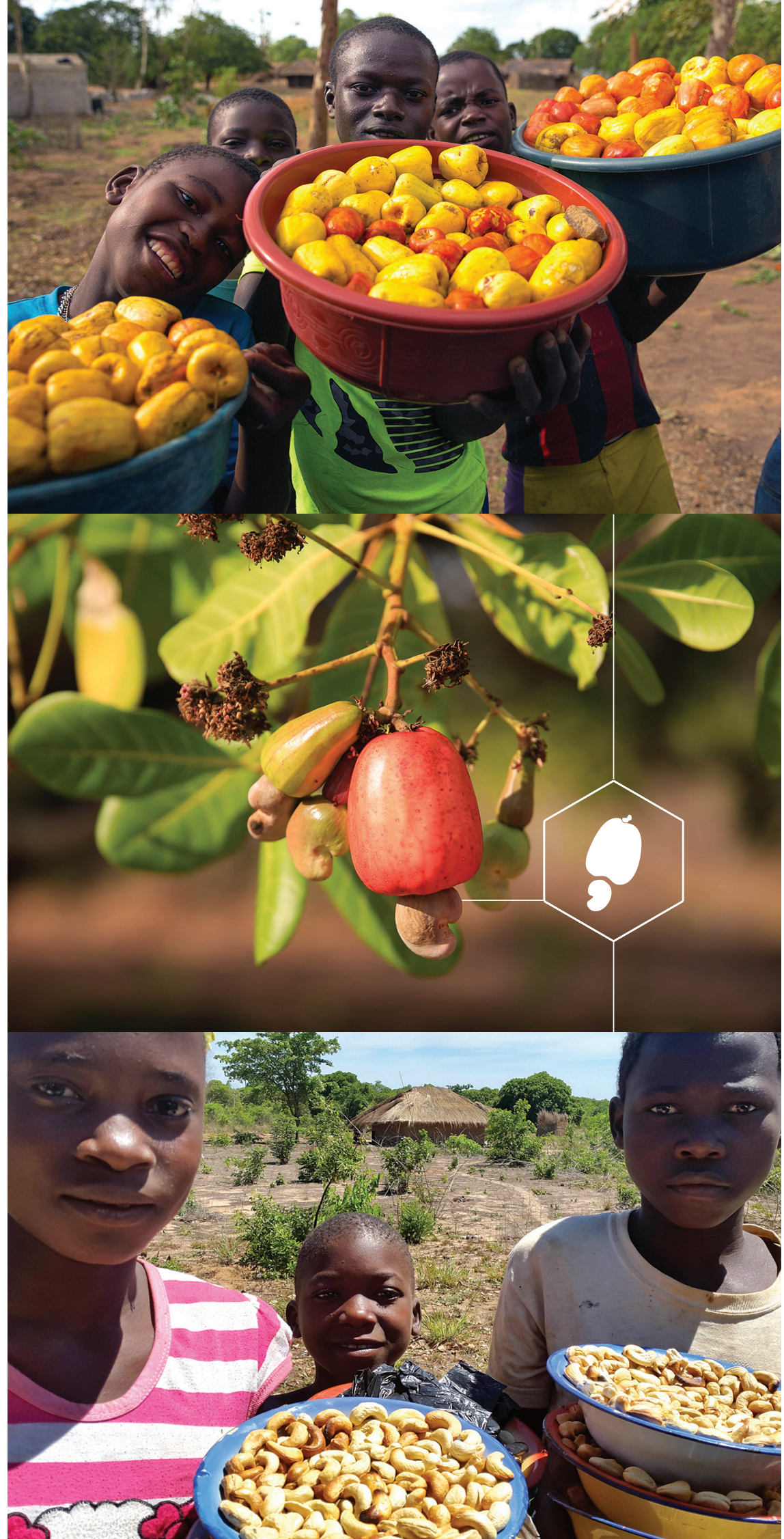




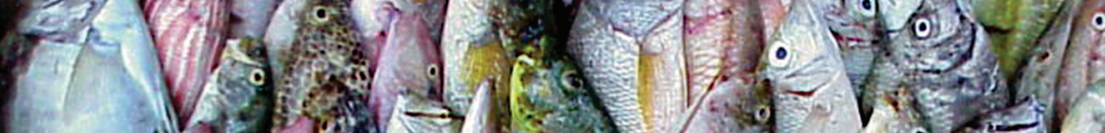

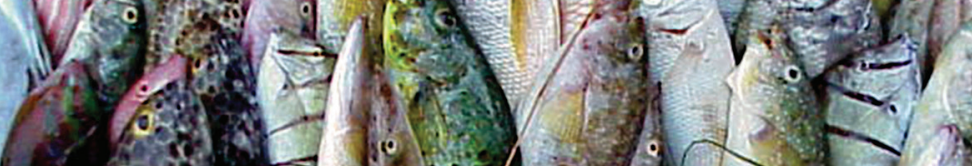

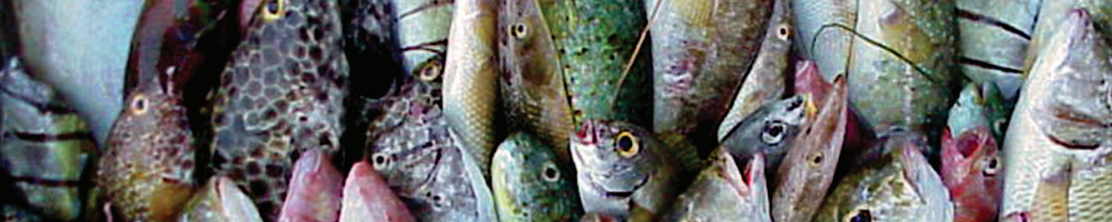

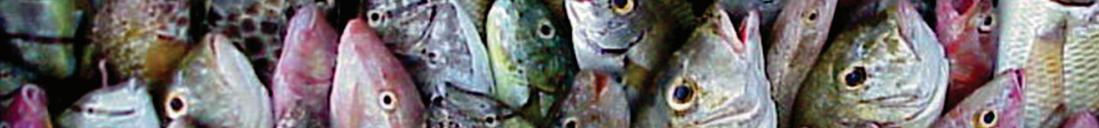

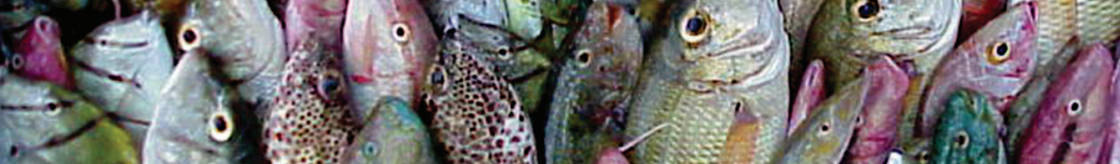

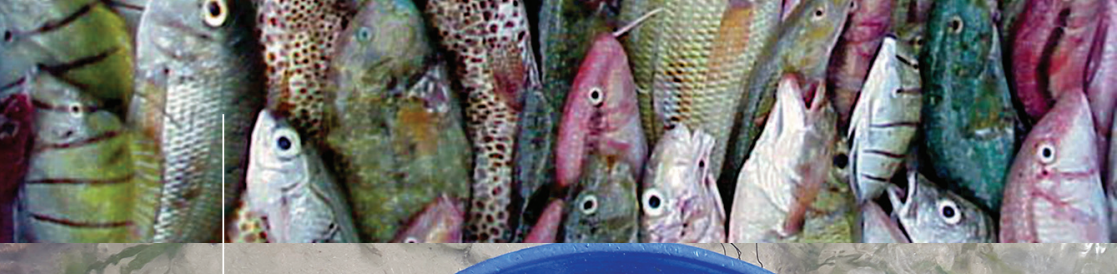
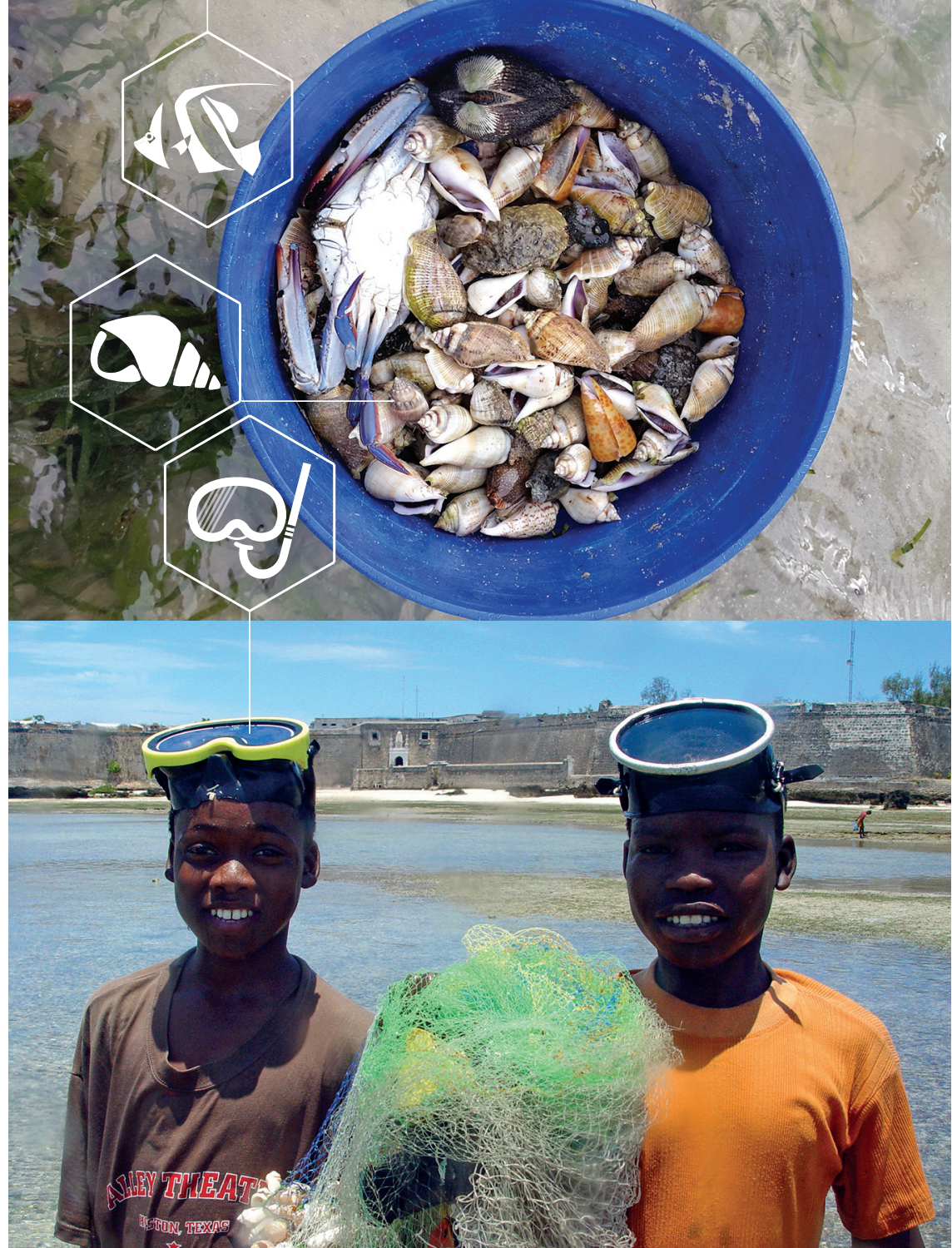
Ao analisar-se o Eixo 2, importa referir o documento Estratégia de Marketing do Turismo para Moçambique (Ministério da Cultura e Turismo, 2017: 44), no qual se estabelecem metas para o quinquénio 2017-2021. Neste, a importância estratégica da Ilha de Moçambique ficou diluída no meio das demais regiões, tendo, inclusivamente, sido relevada como parcela integrante de um dos cinco destinos estratégicos nacionais, no das Quirimbas. Apesar disso, na secção "Acções Específicas a Desenvolver", só se faz referência à Ilha de Moçambique (ibidem, 2017: 35-36). Para contrariar esta diluição nacional, é crucial a criação de uma marca local forte, diferenciadora e autónoma. Entre outras, há uma enorme vantagem que poderá ser muito útil à Ilha: nos últimos anos o país tem sofrido perturbações sociopolíticas de diversas ordens, em particular nos conflitos armados no centro e, mais recentemente, no extremo norte do país, projetando uma imagem de insegurança para o exterior, generalizada a todo o território, retraindo o investimento e o fluxo turístico, mesmo em locais onde essa insegurança é inexistente, como é o caso da llha. Assim, distanciá-la da conjuntura negativa do país através de uma imagem própria, coerente e positiva, poderá devolver-lhe os créditos de local idílico e seguro para visitar, fator essencial na escolha de turistas e investidores (Wade, Mwasaga e Eagles, 2001: 99-100). A promoção dos ativos turísticos da Ilha, tal como em Zanzibar, poderá ser subdividida em dois segmentos: um ligado à cultura e história, outro ao sol e praia. O primeiro focado na promoção das heranças culturais e na grande variedade de património material e imaterial implícito com ênfase na interação e fusão de culturas, manifestado não apenas na arquitetura e no urbanismo (cidades de pedra e cal e de macuti), como, por exemplo, na gastronomia (ciriciri), na música e na dança (tufo e maulide), no artesanato (missangas centenárias garimpadas pelas crianças nas praias) e na literatura (Luís de Camões, Rui Knopfli, entre outros poetas que cantaram a llha). A inscrição na Lista do Património Mundial da UNESCO promove-a como produto turístico de cultura e história de excelência. Será fundamental realçar este estatuto na marcalugar, dignificando-o e conferindo-lhe visibilidade. Ainda neste segmento, haverá que salientar bens fora da llha (a Igreja de Nossa Senhora dos Remédios, o Palácio do Governador e o cemitério árabe na Cabaceira), as aldeias (Jambese, Sancul, Lumbo, Cabaceiras Grande e Pequena) e um traço de singularidade, a integração na grande cultura swahili. 
Poderão integrar-se rotas swahili mais abrangentes, ligando congéneres costeiras e insulares até Zanzibar. Há ainda a possibilidade de integrar outro tipo de rotas, como o das pinturas rupestres da Província de Nampula, das quais são exemplo as diversas inscrições de figuras milenares existentes num afloramento rochoso em Nacavala.

O segundo segmento, sol e praia, englobará o clima tropical, as praias de areia branca com águas transparentes e mornas de cor azul turquesa, os bancos de coral e a biodiversidade, especialmente marinha (ecossistemas coralíferos, cetáceos, entre outros). Poderão promover-se não só locais relativos à Ilha (praias da Alfândega, do Ancoradouro, do Carramo, da Fortaleza), como também das ilhas desertas circundantes (Goa, Sena, Cobras e Sete Paus) e do continente (Lumbo, Sancul e Cabaceira Pequena). A interligação com estes locais insulares e continentais fomentará necessariamente percursos nos dhows. O potencial costeiro poderá ainda proporcionar atividades ligadas ao mergulho de superfície e de profundidade. Este último, tem no mergulho arqueológico um ativo diferenciador, jazendo ao largo da llha diversas embarcações naufragadas, interagindo com o eixo cultural.

As principais atividades económicas (Eixo 3), também podem ser incorporadas de forma a beneficiarem da chancela Muhipiti. Uma vantagem imediata será a utilização de uma imagem de marca graficamente coerente e apelativa, que promova e acredite os produtos endógenos, criando sinergias com os outros eixos. A formação avançada contribuirá, decerto, com investigação sobre estas atividades e respetivos produtos, de forma a otimizar a sua rentabilidade. Já o turismo, poderá ajudar a divulgar e valorizar os produtos através de visitas guiadas aos respetivos processos de recolha e transformação, postos de venda e criação de centros interpretativos. 


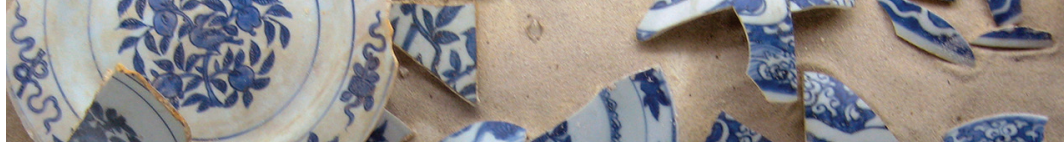
(a) (1)
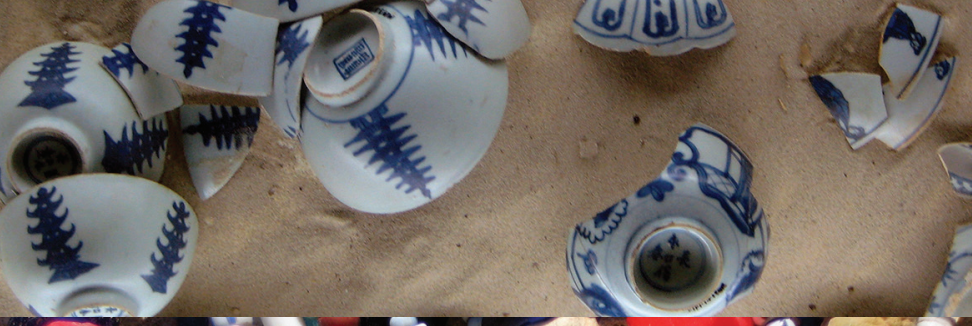

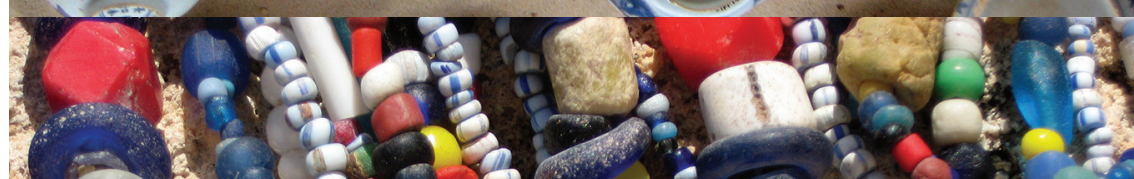
- Than

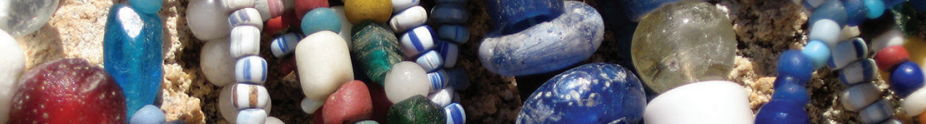
$-x+2$. 3

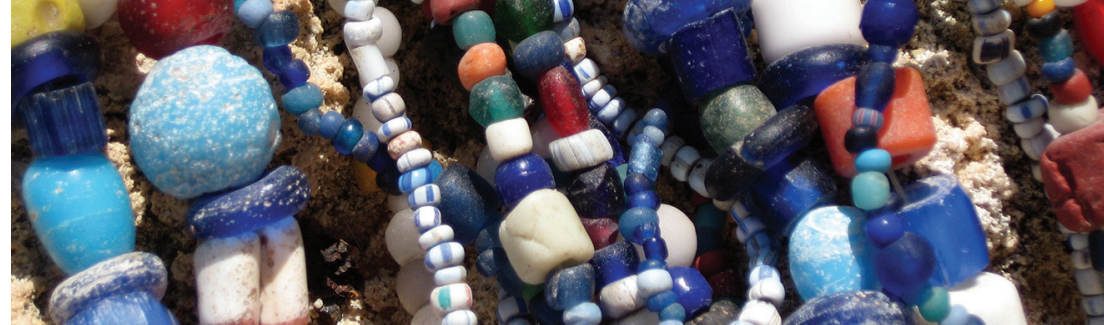
- 12.5. 4 -3 $125=$ - $x^{2}-1$ th

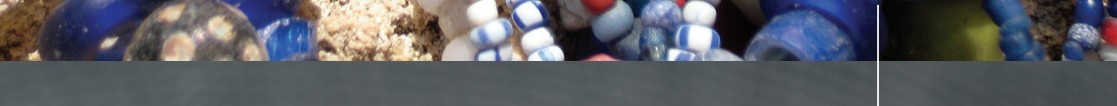




\section{UM SISTEMA DE COMUNICAÇÃO MUHIPITI PARA A ILHA DE MOÇAMBIQUE}

Elencadas algumas das potencialidades e vocações da llha enquanto Muhipiti, torna-se essencial compreender quais poderão ser as bases para o processo de criação da identidade visual desta marca-lugar.

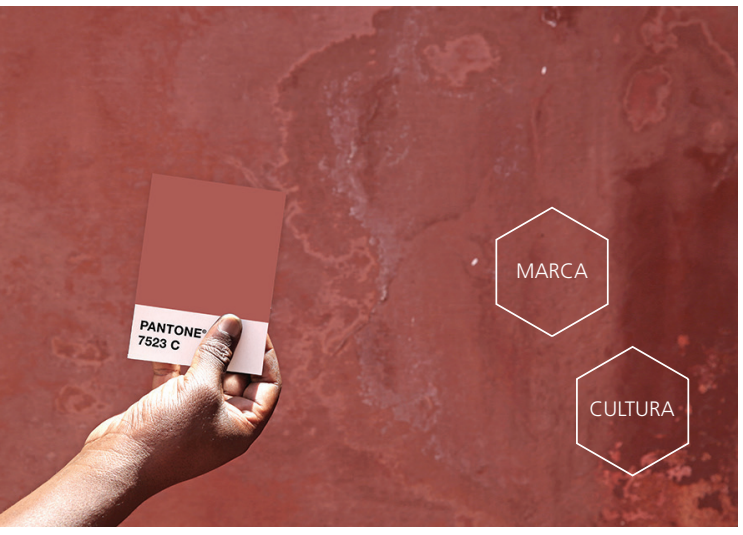

O procedimento criativo precisará de dar resposta a uma série de questões que terão de ser levantadas e analisadas de forma holística pelos diversos intervenientes, incluindo a comunidade, os atores e administradores locais.

O que tornará Muhipiti uma marca-lugar única? Quais os ingredientes essenciais que a permitirão definir, descrever, divulgar inequivocamente? Que cores, iconografia, padrões e texturas? O que poderá constituir um sistema de comunicação Muhipiti coerente nas suas várias dimensões de patrimónios tangíveis e intangíveis? Como promover e dignificar o seu estatuto de Património da Humanidade?

Tecnicamente, o desenho isolado de um logótipo será insuficiente. Ainda que essencial para a aplicação generalizada da marcalugar, este terá de fazer parte de um sistema de comunicação uno que padronize Muhipiti e tudo o que a ele se refira, criando uma linguagem visual coerente, forte e apelativa. 
Nesta análise deverão ter-se em conta fatores culturais específicos, assim como a elevada iliteracia, transmissão de tradição maioritariamente oral, desconhecimento ou difícil acesso a novas tecnologias de informação, características que poderão gerar equívocos de interpretação simbólica e concetual. Como refere Bruno Munari (2006: 10-11) "cada um vê o que conhece". Sugere-se, por isso, a criação de um sistema de comunicação objetivo, de fácil descodificação, que funcione tanto a nível local como internacional, evitando a utilização de códigos complexos para os quais os intervenientes não possuam elementos de descodificação.

Como conclusão-suspensão deste caminho, apresenta-se de seguida um receituário que visa ajudar a compreender imagética e conceptualmente Muhipiti e as suas especificidades. Poderá ser um ponto de partida para quem, de preferência num futuro próximo e refinando a receita, defina uma marca-lugar que dignifique e promova a pequena Ilha Muhipiti e o seu vasto e inefável património cultural.
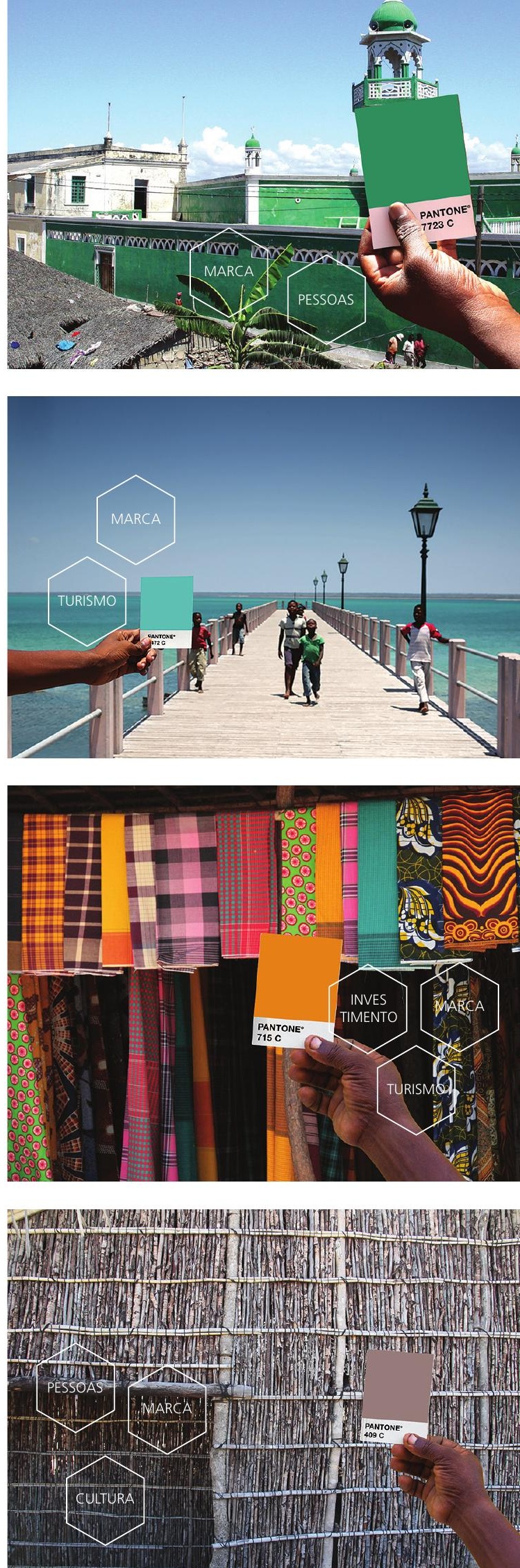

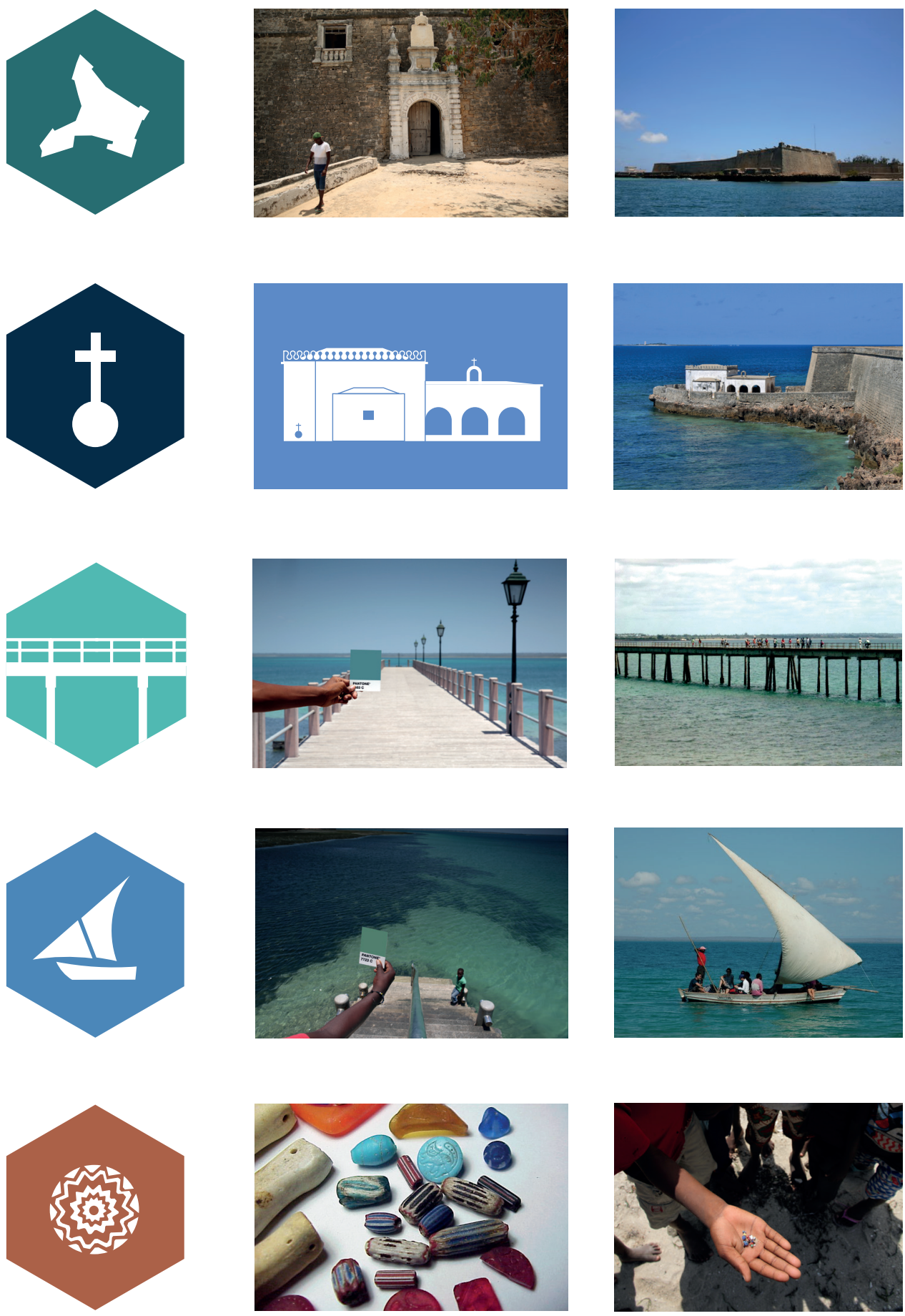

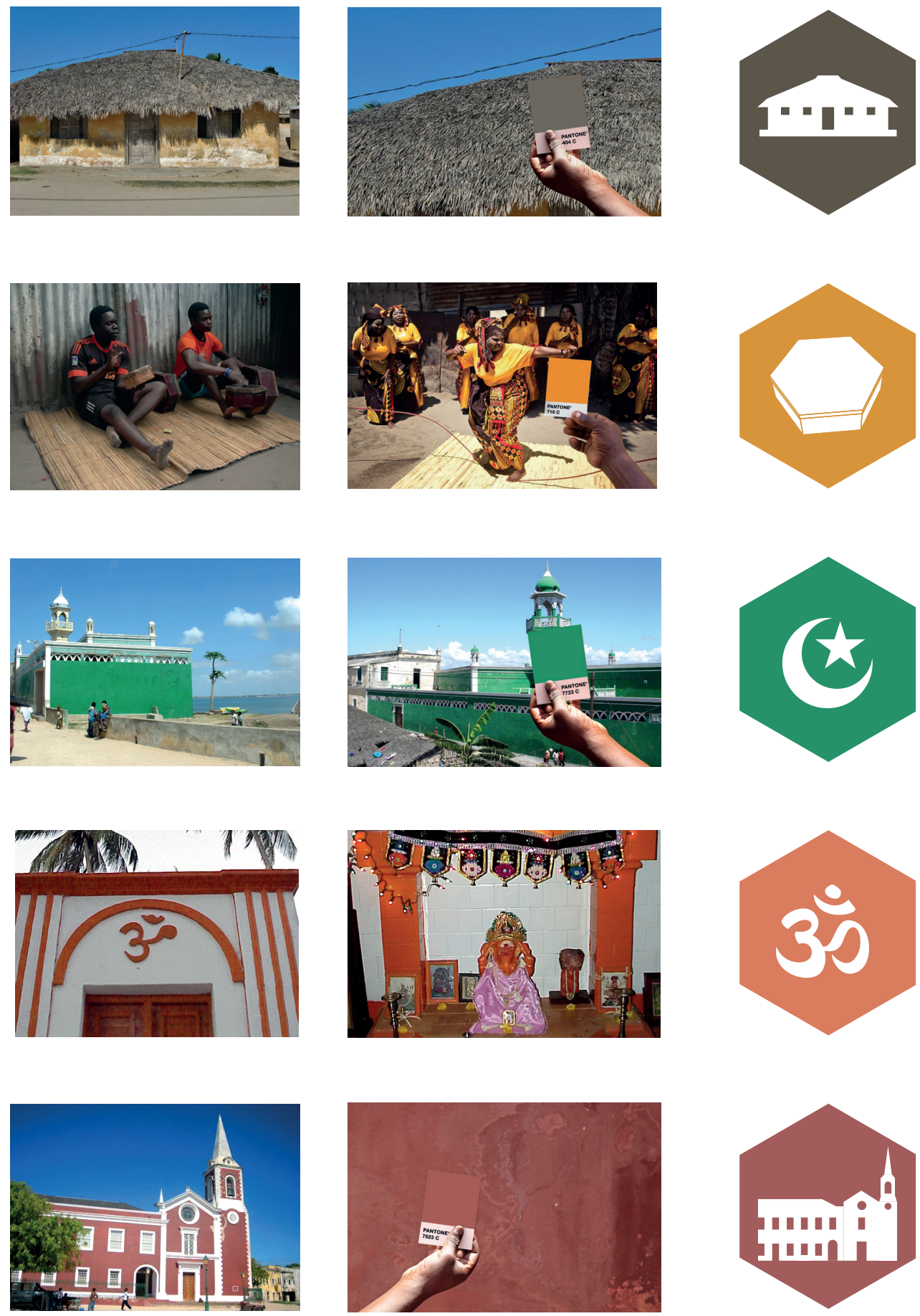


\section{INGREDIENTES PARA MUHIPITI}

Escolha-se uma ilha, não muito grande, com significativo passado histórico.

Tenha-se o cuidado de assegurar que uma fortaleza, alguns naufrágios, objetos e utensílios existam, para registar o passado.

Rodeie-se de verde-azul, em nuances que unam os céus e os mares.

Coloque-se suficientemente perto do continente, de forma a poder com ele comunicar. Erga-se uma ponte que permita o acesso de pessoas e veículos, em ambos os sentidos.

Retire-se pedra coral de metade e construam-se casas e edifícios na outra metade.

Aproveite-se do saque a cratera ferida, para aí construir os bairros tradicionais de macuti, e faça-se a ilha pulsar. Habite-se a ilha com diferentes culturas, credos, modos de estar, diferentes expressões artísticas, colocando todas em interação, mesclando até aos limites das suas identidades. Pintem-se as caras das mulheres de m'siro e vistam-se de capulanas garridas, contas e lenços que coroem o conjunto. 
Das árvores talhem-se dhows, barcos que permitam aliviar o monocromático dos dias, coreografando o ritmo das marés.

Polvilhe-se o mar de missangas e contas, que contem as histórias de viagens que por ali passaram. As marés encarregar-se-ão de as fazer falar.

Reúnam-se os fragmentos do passado e edifiquem-se os museus que permitam preservá-los no presente, continuando a narrá-los no futuro.

Mantenham-se vivas as tradições, danças de tufo, rituais e tudo o mais que torne esta ilha única.

Reclame-se o nome Muhipiti.

Leve-se Muhipiti para fora, ultrapassando os limites da ponte, coloque-se em aviões, navios, nas estórias dos que por ali passam, no artesanato que transportam consigo. Conte-se a história Muhipiti fora da ilha, inspirando novos viajantes a por ali passar, e outros inspirados por estes. Permita-se que Muhipiti tenha um futuro, que não se limite ao somatório da sua geografia, do seu património, do seu passado.

Muhipiti compreenderá quem é e tornar-se-á maior. 


\section{REFERÊNCIAS BIBLIOGRÁFICAS}

ANHOLT, Simon (2006) Competitive Identity: The New Brand Management for Nations, Cities and Regions. Basingstoke: Palgrave Macmillan.

KAVARATZIS, Mihalis (2004), "From City Marketing to City Branding: Towards a Theoretical Framework for Developing City Brands" , Place Branding 1 (1): 58-73. Consultado a 05.04.2017, em: https://doi.org/10.1057/ pb.2008.3.

KAVARATZIS, Mihalis (2009), "Cities and Their Brands: Lessons from Corporate Branding", Place Branding and Public Diplomacy 5 (1): 26-37. Consultado a 05.04.2017, em: https://doi.org/10.1057/ pb.2008.3.

Ministério da Cultura e Turismo (2017), Estratégia de Marketing do Turismo (2017-2021). Consultado a 05.04.2017, em:http://www. portaldogoverno.gov.mz/por/content/download/1436/12137/ version/1/file/Plano+Estrategico+Desenvolvimento+Turismo+lngl\%C3\%AAs.pdf.

MUNARI, Bruno (2006), Design e Comunicação Visual: contribuição para uma metodologia didática. São Paulo: Martins Fontes.

Serengeti Advisers and Acorn Tourism Consulting (2010), "Zanzibar Destination Marketing Strategy Final Report". Consultado a 05.04.2017, em: http://www. best-dialogue.org/publication/zanzibar-destinationmarket-strategy/.

UNESCO (2000), "The Stone Town of Zanzibar: WHC Nomination Documentation". Paris: UNESCO. Consultado a 05.04.2017, em: http://whc.unesco.org/uploads/nominations/173rev.pdf.

WADE, Derek J.: MWASAGA, B. C.; EAGLES, Paul F.J. (2001), "A history and market analysis of tourism in Tanzania", Tourism Management, 22 (1): 93-101. Consultado a 05.04.2017, em: https://doi.org/10.1016/ S0261-5177(00)00019-4.

WANJIRU, Evalyne (2006), "Branding African countries: A prospect for the future", Place Branding, 2 :84-95. Consultado a 05.04.2017, em: https://doi.org/10.1057/palgrave.pb.5990047.

YOUDE, Jeremy (2009), "Selling the State: State Branding as a Political Resource in South Africa", Place Branding and Public Diplomacy, 5 (2): 126-40. Consultado a 05.04.2017, em: https://doi.org/10.1057/ pb.2009.5. 